\title{
Pediatric glaucoma: current perspectives
}

This article was published in the following Dove Press journal:

Pediatric Health, Medicine and Therapeutics

26 May 2014

Number of times this article has been viewed

\section{Giorgio Marchini \\ Marco Toscani \\ Francesca Chemello \\ Eye Clinic, Department of Neurological and Movement Sciences, University of Verona, Verona, Italy}

Correspondence: Giorgio Marchini Eye Clinic, AOUI - Borgo Trento Hospital, Piazzale Aristide Stefani, I, 37 I 26 Verona, Italy

Tel +39458122340

$\mathrm{Fax}+39458122025$

Email giorgio.marchini@univr.it
Abstract: "Childhood glaucoma" is a heterogeneous group of severe pediatric conditions often associated with significant visual loss and characterized by elevated intraocular pressure (IOP) and optic-disk cupping. Successful IOP control is crucial but challenging and most often achieved surgically, with medical therapy playing a supportive role. There are many classifications of childhood glaucoma, but they can simply be divided into primary, in which a developmental abnormality of the anterior chamber angle only exists, and secondary, in which aqueous outflow is reduced due to independent mechanisms that secondarily impair the function of the filtration angle. The worldwide prevalence of childhood blindness ranges from $0.03 \%$ in high-income countries to $0.12 \%$ in undeveloped countries. The majority of cases do not have an identified genetic mutation and, where the mutation is known, the genes often account for only a small proportion of cases. Several pathogenetic mechanisms are known to contribute to the development of childhood glaucoma. Whatever the cause, it results in a reduced aqueous outflow at the level of the trabecular meshwork. Age of onset and magnitude of the elevated IOP largely determine the clinical manifestation the high variability of clinical manifestations. Glaucoma from any cause in a neonate and infant is characterized by the classic triad of epiphora, photophobia, and blepharospasm, and could be associated with eye enlargement (buphthalmos) and Haab striae. The eye examination, usually performed under general anesthesia, includes: tonometry, anterior-segment examination, gonioscopy, corneal diameter and axial length measurement, dilated fundoscopy with optic-nerve-head evaluation. Medical therapy, considering the high frequency of side effects, is generally used as temporizing IOP-lowering treatment before surgery or as adjuvant treatment postoperatively in case of partially successful procedures for refractory glaucomas. Surgery is the nodal point of the management of refractory childhood glaucoma, so it is crucial to opt for a forward-looking strategy to reach the target IOP and minimize the visual loss.

Keywords: childhood glaucoma, congenital glaucoma, glaucoma surgical therapy, childhood visual loss

\section{Introduction}

"Childhood glaucoma" is a rare and severe pediatric condition often associated with significant visual loss. It consists of a heterogeneous group of diseases characterized by elevated intraocular pressure (IOP) and optic-disk cupping. Successful control of IOP is crucial but challenging and most often achieved surgically, with medical therapy playing a supportive role.

\section{Classification}

There are many classifications of childhood glaucoma, but they can simply be classified as primary, in which a developmental abnormality of the anterior chamber (AC) 
angle only exists, and secondary, in which aqueous outflow is reduced due to independent mechanisms that secondarily impair the function of the filtration angle ${ }^{1}$ (Table 1). Primary glaucoma in children is generally divided based on age of onset into primary congenital glaucoma (PCG), from birth to early childhood, and juvenile primary open-angle glaucoma (JOAG), from 4 years to early adulthood. Secondary glaucoma includes a variety of conditions resulting from damage to the aqueous outflow system due to congenital or acquired ocular diseases or systemic disorders.

Table I Classification of childhood glaucoma

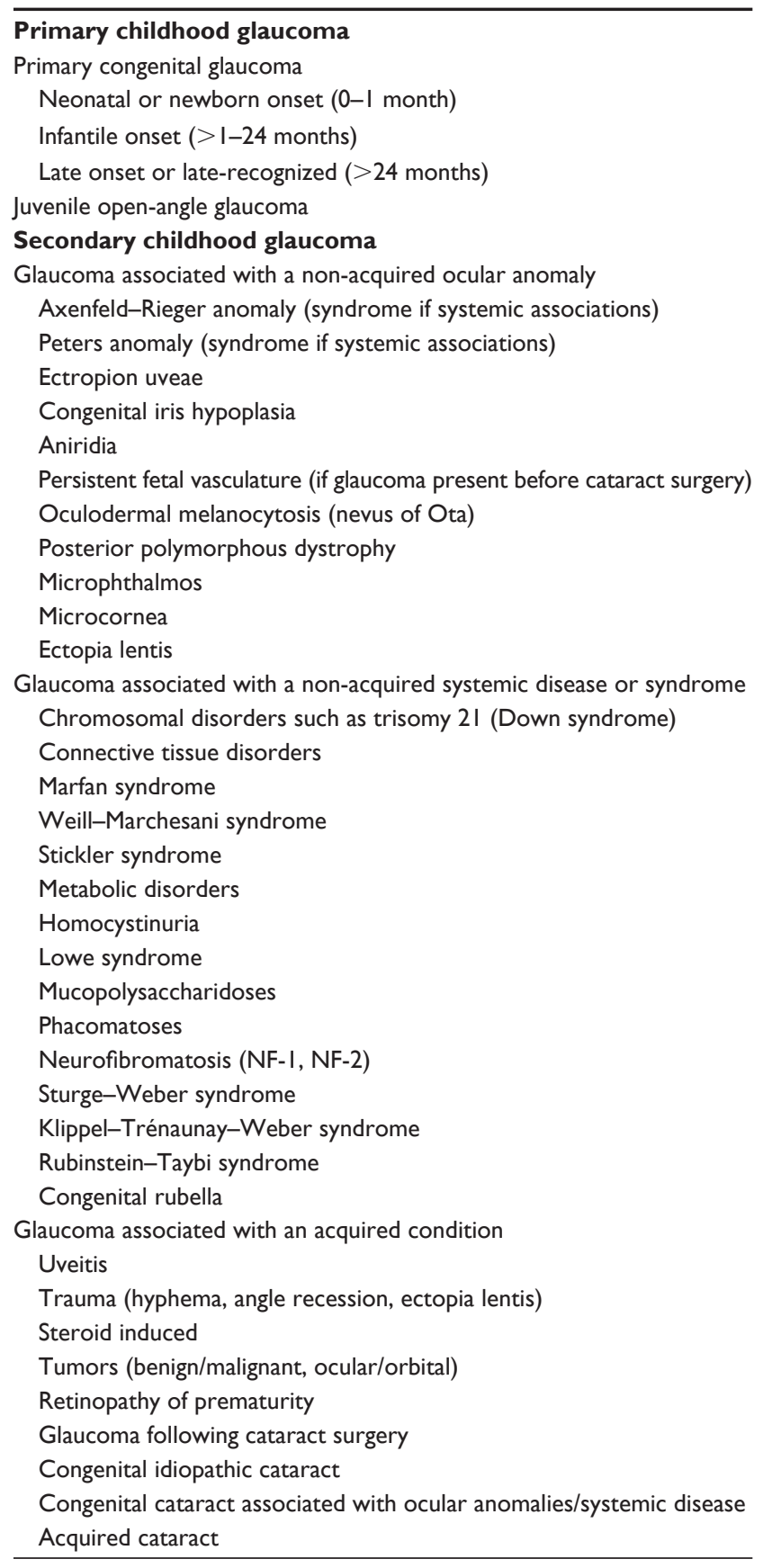

The worldwide prevalence of childhood blindness ranges from $0.03 \%$ in high-income countries to $0.12 \%$ in undeveloped countries. The causes of severe visual impairment and blindness are varied and complex: glaucoma accounts for $4.2 \%-5.0 \%$ of blindness in the pediatric population. ${ }^{2-4}$

\section{Genetics and pathogenesis}

The genetics of glaucoma is a developing area of research with most of the genetic tendency for glaucomas yet to be disclosed. Further, in most populations, the majority of cases do not have an identified genetic mutation, and, where the mutation is known (GLC3A, GLC3B, and GLC3C loci), the genes often account for only a small proportion of cases. ${ }^{5}$ However the identification of genes and the spectrum of mutations causing childhood glaucoma will have both basic and clinical relevance. It may help in early treatment and diagnosis, carrier detection and genetic counseling, population screening, and prenatal diagnosis, for establishing genotypephenotype correlations and prognosis, understanding pathogenesis, and the development of better treatment strategies.

Several pathogenetic mechanisms are known to contribute to the development of childhood glaucoma. Regardless of the cause, it results in a reduced aqueous outflow at the level of the trabecular meshwork (TM). TM formation begins around the fourth month of gestation. The mesenchymal cells of the TM form a wedge-shaped structure between the corneal endothelium and the deeper stroma. Schlemm's canal (SC) forms from a venous plexus anterior to the TM which becomes visible in the 16th week of gestation and by 24 weeks it is present throughout the entire circumference. By 36 weeks, SC and the outer collecting channels are clearly defined and connected by intercanalicular links. The development of this system continues postnatally: an adult-like configuration is achieved by 8 years. ${ }^{6-8}$ In PCG, the developmental arrest of tissues derived from cranial neural crest cells can lead to anterior iris insertion, thickened trabecular beams, compressed trabecular sheets, iris processes, and insertion of the fibers of the ciliary muscle into the TM.

\section{Clinics}

The age of onset and the magnitude of the elevated IOP largely determine the clinical manifestation and their high variability. Very high IOP can present dramatically in a newborn as cloudy, enlarged corneas. A slower rise in IOP results in a less acute presentation with buphthalmos but no corneal clouding or photophobia. The timing of the pressure rise influences the clinical features, owing to the limited potential of the young eye to deform. 
Glaucoma from any cause in a neonate or infant is associated with the classic triad of epiphora (excessive tearing), photophobia (hypersensitivity to light), and blepharospasm (squeezing of the eyelids). Any combination of these symptoms should arouse suspicion of glaucoma in an infant or child. These conditions are secondary to the corneal irritation that accompanies corneal epithelial edema caused by elevated IOP. Beyond the age of 3 years, children are more likely to present with progressive myopia or strabismus.

Epiphora may at first be attributed to a non-patent tear drainage system, which is a common condition. Photophobia commonly occurs and may be of gradual or sudden onset. The parents may first notice that their baby keeps the eyes closed when exposed to sunlight. Moderate photophobia may be noticed indoors as well; the baby will often keep the eyes closed even while eating. Severe photophobia will cause the baby to keep the eyes closed constantly or to hide the face from bright lighting or even from ordinary lighting. The baby may also be seen to rub the eyes frequently during the period of apparent discomfort.

Enlargement of the eye (buphthalmos) occurs under the influence of the elevated IOP. During the first 3 years of life, corneal and scleral collagen are still immature and the young eye is vulnerable to the effects of increased IOP with the major enlargement occurring at the corneoscleral junction. As the cornea and limbus enlarge, Descemet's membrane and the corneal endothelium are stretched and this can result in linear ruptures (Haab striae). Haab striae are usually concentric to the limbus in the periphery and more typically horizontal centrally near or across the visual axis, where associated opacification and resultant astigmatism can limit the visual potential.

Glaucomatous optic-disk cupping in infants differs from that in adults in two ways: it occurs earlier and more rapidly, with severe excavation possible at birth and it is often reversible if IOP reduction occurs before irreversible nerve atrophy. The younger the child is, the greater the potential for disk-cupping reversal. ${ }^{9}$

The history of blepharospasm, photophobia, and tearing is very useful in arousing the suspicion of glaucoma and in distinguishing it from other conditions. The suspicion of glaucoma in a child should always be treated seriously and with urgency to minimize visual impairment. This requires examination in a clinic or under anesthesia depending on the child's ability to cooperate.

\section{Diagnosis}

A complete ocular assessment including slit-lamp examination, applanation tonometry, and optic-nerve-head evaluation can usually be performed in the office in children over the age of 5 years and, with some training, in children as young as 3 years.

Other historical information of importance is a family history of glaucoma, parental consanguinity, associated congenital defects, maternal history of infection (rubella) during pregnancy, and birth history (forceps use). ${ }^{10}$ In older children, a history of trauma, ocular surgery, or corticosteroid use may be relevant.

The aim of the initial assessment is to rule out glaucoma or establish that enough evidence for glaucoma exists to justify an examination under anesthesia (EUA) for a more complete examination and surgery if indicated. All anesthetic drugs alter the IOP of patients with PCG, seemingly in relation to the level of anesthesia and as a direct function of their effect on hemodynamic changes and cardiovascular tone. Multiple exposures to general anesthesia in infants and young children may adversely affect the developing brain and may cause long-term neurocognitive changes. However, the possible anesthetic neurotoxicity concerns should be considered within the context of the high risk of blindness from glaucoma in children not adequately assessed or surgically managed. ${ }^{11-14}$ EUAs performed solely to make the diagnosis prior to referral for surgery should be avoided; it is best that the ophthalmologist undertaking the initial EUA be capable of performing the definitive surgery under the same anesthetic, to avoid unnecessary anesthesia and a delay in treatment.

The examination of a child suspected to have glaucoma should begin by assessing the overall appearance and visual behavior of the infant or child, including the signs of nystagmus or strabismus. Ambient illumination can be reduced to allow a neonate or infant to open their eyes, permitting a more complete examination by penlight or portable slit lamp. Through observation alone it may be possible to assess the presence of corneal edema, lacrimation, photophobia, blepharospasm, and the relative and actual size of both eyes. When indicated, it is important to examine the patient's parents, as the presence of subtle signs of anterior-segment dysgenesis in the parents may change the genetic advice given and alter the management of subsequent siblings.

Measuring the IOP in children can be challenging, as it is potentially influenced by many factors such as type of tonometer, cooperation, eye movements, anesthesia, and corneal conditions like edema or opacities. Therefore, IOP is among the least accurate and most variable of all the parameters measured when assessing a child for glaucoma. The diagnosis of pediatric glaucoma should never be made 
on the basis of elevated IOP alone but based on the overall clinical findings and investigation results.

The gold standard for measuring IOP is Goldmann applanation tonometry using a Perkins handheld tonometer, during EUA, with a blue filter after installation of topical anesthesia and fluorescein. The "Tono-Pen" ${ }^{\circledR}$ " (Reichert Technologies, Depew, NY, USA) is an electronic tonometer often used with pediatric patients, but it is known to overestimate the IOP in children compared with applanation tonometry in both normal children and those with glaucoma. ${ }^{15-17}$ The iCare portable rebound tonometer (iCare Finland Oy, Helsinki, Finland) can measure IOP without the installation of topical anesthetic in both upright and supine positions by rolling the baby into a lateral position, and may be better tolerated than noncontact methods. It has a similar reliability to a Tono-Pen, with a tendency to overestimate IOP in known or suspected glaucoma cases compared with applanation tonometry. ${ }^{18-24}$

Ideally, the eyes should be in the primary position and motionless as pressure readings may be altered by eye movements. Avoid measuring the IOP when using a lid speculum or when the baby is crying or squeezing his or her lids, as all of these may falsely elevate the IOP. The IOP should be measured several times in both eyes and prior to pupil dilation, as it can also affect the measurements. It is advisable to use the same type of tonometer for serial examinations.

Anterior-segment examination of a neonate or infant is a very important part of the examination, not only with regard to the diagnosis of glaucoma but also in determining the type of glaucoma.

Medications may help clear the cornea and improve visualization of anterior-segment structures and angle features with gonioscopy. The cornea should be examined for the presence of posterior embryotoxon, corneal enlargement or edema, and Descemet's membrane splits (Haab striae). Excluding primary corneal disease is important, and a useful distinguishing feature is the absence of corneal or ocular enlargement.

Examining the iris and pupil for abnormalities is fundamental to determine the type of glaucoma, as they may suggest a secondary cause of glaucoma. Iris abnormalities, such as peripheral corneal adhesions, may indicate the presence of Axenfeld-Rieger anomaly, especially in the setting of posterior embryotoxon. Diffuse iris atrophy may indicate a subtle variant of aniridia, whereas inferior sectoral iris atrophy or distortion may indicate a colobomatous process. Similarly, determining the coexistent presence of lens opacities and glaucoma may influence the diagnosis and the choice of glaucoma surgery.
The purpose of gonioscopy is to differentiate primary from secondary glaucoma. ${ }^{25}$ In other words, it is crucial in making the correct diagnosis, as this determines the most appropriate management and prognosis. In the normal newborn eye, the iris usually inserts posterior to the scleral spur. The anterior extension of the ciliary body is seen as a distinct band anterior to the iris insertion. The iris insertion into the angle is flat, because the angle recess has not yet matured. The formation of the angle recess, characteristic of the adult angle, in which the iris turns slightly posteriorly before inserting into the ciliary body, develops in the first 6 to 12 months of life. The TM has no acquired pigmentation and appears thicker and more translucent than that of the adult. ${ }^{26,27}$

In PCG, the immature angle appearance is thought to result from the developmental arrest of tissues derived from cranial neural crest cells in the third trimester of gestation. The severity of angle abnormality depends on the stage at which the angle development has been arrested. The iris insertion of eyes with PCG is higher than normal and the peripheral iris inserts to the TM and the scleral spur is not visualized. The level of insertion may vary in different areas of the angle, and, in very immature angles, pale amorphous tissue may be present in the angle.

Corneal enlargement usually occurs before 3 years of age. Serial corneal diameter measurements are useful in establishing the diagnosis and in the monitoring the progression of glaucoma. The normal horizontal neonatal diameter is around $10 \mathrm{~mm}$, increasing by about $1 \mathrm{~mm}$ during the first year of life. A corneal diameter greater than $11 \mathrm{~mm}$ in a newborn and $12 \mathrm{~mm}$ in an infant less than 1 year old is very suggestive of raised IOP and with Haab striae it is diagnostic. A measurement of greater than $13 \mathrm{~mm}$ in a child of any age is abnormal. During EUA, the corneal diameter is measured with calipers from limbus to limbus - usually only horizontal corneal diameter or both horizontal and vertical. An increasing corneal diameter in a vulnerable eye suggests inadequate control of IOP and requires further treatment.

The definitive role for pachymetry in the evaluation of childhood glaucoma is currently uncertain. Central corneal thickness should not be used to "adjust" an IOP measurement, as in the adult, but rather taken into consideration in the overall context of the examination.

In general, thinner corneas tend to cause tonometers to underestimate IOP, whereas thicker corneas tend to cause overestimation of IOP compared with the "true" value. Central corneal thickness can be increased due to stromal edema, thickening (congenital or postoperative), or scarring. Children with PCG and JOAG have thinner central corneas 
than normal subjects. ${ }^{28-30}$ In contrast, corneal thickness is known to be increased in patients with congenital aniridia and in aphakia following congenital cataract surgery. ${ }^{31-34}$

Dilated fundoscopy is performed once the IOP has been measured and anterior-segment examination has been completed, as dilation can spuriously elevate the IOP and alter the angle appearance. The most important and sensitive parameter for both diagnosis and determination of progression in pediatric glaucoma is the optic-disk appearance, because it is not influenced by anesthesia or by the effect of growth. Optic-nerve size, the cup-disk ratio, focal areas of rim loss, and nerve fiber layer defects following dilation should be carefully recorded. ${ }^{35-37}$ An increase in disk cupping is definite evidence of poorly controlled glaucoma and the need for further treatment, regardless of IOP measurement obtained.

Another evidence of glaucoma is the loss of hypermetropia or the presence of myopia. Progressive myopia may suggest inadequate IOP control, especially if seen in the setting of progressive axial length increase. ${ }^{38-43}$

\section{Classification}

\section{Primary congenital glaucoma}

"PCG" refers to a specific form of developmental glaucoma that has an isolated maldevelopment of the TM (isolated trabeculodysgenesis) not associated with other developmental ocular anomalies or ocular disease that can raise the IOP (Figure 1). PCG is classified, according to age of onset of signs, into: neonatal or newborn onset ( $0-1$ month), infantile onset ( $>1-24$ months), and late onset or late recognized $(>2$ years $)$.

PCG is the most diffused non-syndromic glaucoma in infancy, ${ }^{44,45}$ but it has a variable reported incidence worldwide. A higher prevalence has been observed in those cultures and groups with an increased rate of consanguinity, especially in those groups in which cousin-cousin marriages are common. PCG occurs in 1 per 10,000-20,000 live births

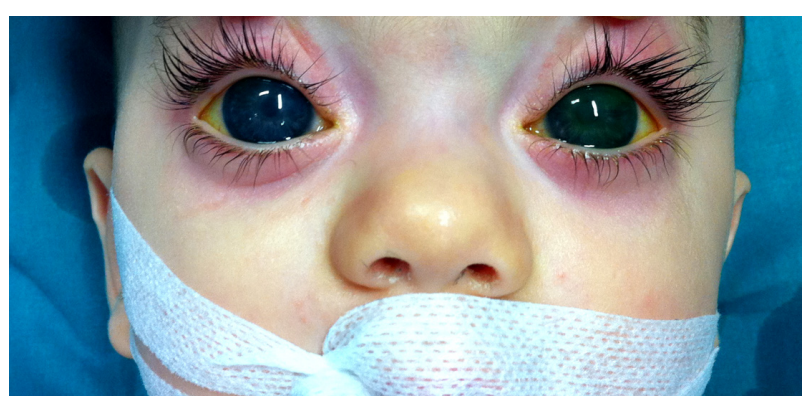

Figure I Bilateral buphthalmos in PCG. in Western countries. ${ }^{46,47}$ The incidence rises in the Middle East to 1 per 8,200 live births in Palestinian Arabs and 1 per 2,500 live births in Saudi Arabians. The highest reported incidence is 1 per 1,250 in Slovakian Gypsies. ${ }^{48}$

It is usually bilateral (70\%), with the severity of involvement frequently asymmetrical. There is a slightly higher prevalence in males, but familial cases tend to have an equal sex distribution. ${ }^{49}$ Most cases of PCG are sporadic. A family history of glaucoma is reported in $10 \%-40 \%$ of cases associated with autosomal recessive inheritance and variable penetrance ranging from $40 \%$ to $100 \%$. The risk of PCG in siblings and offspring in patients with no history of parental consanguinity is low $(<5 \%)$, but it is prudent to examine the siblings and offspring of patients, especially in the first 6 months of life. To date, three PCG loci have been identified. GLC3A is the major locus for PCG, accounting for $85 \%-90 \%$ of all familial cases. ${ }^{50}$ It has been mapped to the short arm of chromosome $2 \mathrm{p} 21$, the GLC3B locus to chromosome $1 \mathrm{p} 36$, and GLC3C to chromosome $14 \mathrm{q} 24$, with more loci speculated to exist. Mutations of the GLC3A locus affect the gene $C Y P 1 B 1$ which encodes for an enzyme cytochrome $\mathrm{P} 4501 \mathrm{~B} 1$ that has been postulated to participate in the development and function of the eye. ${ }^{51,52}$ CYP1B1 mutations are more commonly seen among familial rather than sporadic cases, and they are associated with a variable expressivity and penetrance.

The pathogenesis of PCG remains uncertain. The immature angle appearance results from the developmental arrest of tissues derived from cranial neural crest cells in the third trimester of gestation. Obstruction to outflow was thought to be due to the presence of an impermeable membrane (Barkan's membrane) but this has never been verified histopathologically. Known histopathological changes in PCG include an anterior iris insertion, thickened trabecular beams, compressed trabecular sheets with loss of intertrabecular spaces, iris processes, and insertion of the fibers of the ciliary muscle into the TM. ${ }^{53,54}$

PCG usually presents in neonates or infants, with the majority presenting at less than 6 months of age. Clinically, PCG is characterized by elevation of IOP, which causes stretching of the tissues of the eye and enlargement of the globe (buphthalmos). The enlargement of the globe and stretching of the cornea can produce breaks in Descemet's membrane, known as "Haab striae". The elevated IOP also causes corneal edema, which manifests with epiphora and photophobia. Blepharospasm is likely a result of the photophobia. Children with PCG usually present for evaluation because their parents notice something unusual about 
the appearance (corneal opacification or enlargement of the eye) of the patient's eyes or their behavior (photophobia and blepharospasm). The severity of the signs and symptoms varies depending on the duration and magnitude of the IOP elevation. Further, the timing of IOP elevation also affects the signs, as a child with late-onset PCG after the age of 3 years will not present corneal enlargement.

Gonioscopy of the eye with PCG reveals an anterior insertion of the iris directly into the TM. The iris insertion is typically flat, and it may vary at different areas of the angle, with some portions of the iris inserting anterior and other areas posterior to the scleral spur. Changes seen due to the physical stretching of structures from elevated IOP include a thin and hypopigmented iris stroma, a peripheral scalloping of the posterior pigmented iris layer and hyperemic iris vessels with circumferential vessels running tortuously in the peripheral iris or on the ciliary body. ${ }^{55}$

\section{Juvenile primary open-angle glaucoma}

"JOAG" is a relatively rare form of childhood glaucoma, accounting for only $0.2 \%$ of childhood glaucoma cases. It typically presents after 4 years of age and up to 35 years. It is classified as a primary glaucoma of childhood, along with PCG. There is often a strong family history of glaucoma, and it is often inherited as an autosomal dominant trait. Up to $20 \%$ of patients have mutations of the MYOC (myocilin)/TIGR (trabecular meshwork-inducible glucocorticoid response) gene at the GLC1A locus on chromosome 1q23.5. Although it is not well understood how mutations in the MYOC gene cause glaucoma, they appear to do so by affecting trabecular outflow. ${ }^{56}$

JOAG differs from primary open-angle glaucoma in its age of onset and magnitude of IOP elevation. JOAG is typically asymptomatic and is discovered incidentally on routine eye examination or screening due to a family history. Although JOAG is a bilateral disease, there can often be marked asymmetry between the two eyes.

Typically, these patients present optic-disk excavation and an extremely high IOP, sometimes greater than $40-50 \mathrm{mmHg}$, with a normal angle appearance and no signs of other ocular anomalies or systemic disease. As the disease presents after the age of 4 years, there are no signs typically seen in PCG, such as corneal edema and enlargement, Haab striae, or any other symptoms usually associated with congenital glaucoma.

\section{Secondary childhood glaucoma}

Secondary childhood glaucomas occur as the result of conditions of ocular anomalies present at birth, which may or may not be associated with systemic signs, or systemic diseases present at birth. This category also includes acquired conditions that are not inherited or congenital but which develop after birth. Glaucoma that develops after cataract surgery is excluded from the acquired-condition category to highlight its frequency.

\section{Glaucoma associated with non-acquired ocular anomalies}

Glaucoma related to congenital ocular anomalies may be present at birth or may develop over time, so regular lifelong monitoring is necessary. A variety of congenital ocular anomalies are associated with glaucoma and some also have associated systemic conditions. These anomalies include the following.

"Axenfeld-Rieger anomaly" refers to usually bilateral abnormalities of the peripheral cornea, peripheral iris, and angle. Clinically, posterior embryotoxon (prominent Schwalbe's line) with iris attachments is seen. "AxenfeldRieger syndrome" refers to these ocular features in association with systemic anomalies such as hypertelorism, periumbilical skin folds, and dental abnormalities. ${ }^{57,58}$

"Peters anomaly" is a mesenchymal dysgenesis of the anterior segment, presenting with a spectrum of ocular abnormalities. This condition is characterized by the presence of a congenital central corneal opacity with defects in stroma, Descemet's membrane, and the endothelium. ${ }^{59}$ Peters anomaly can be associated with systemic abnormalities (Peters Plus Syndrome).

"Aniridia" is a bilateral disorder characterized by the variable absence of a normal iris, often associated with other ocular anomalies (optic-nerve hypoplasia, keratopathy, early onset cataract and glaucoma). ${ }^{60}$

Other conditions that may be associated with glaucoma are ectropion uveae, persistent fetal vasculature, microcornea, sclerocornea, and those anterior-segment anomalies that do not fit into any recognized category. ${ }^{61-64}$

\section{Glaucoma associated with non-acquired systemic disease or syndrome}

Systemic disease present at birth may be associated with ocular signs that include glaucoma.

"Sturge-Weber syndrome" (SWS), or encephalotrigeminal angiomatosis, is a congenital neurocutaneous vascular syndrome, which can potentially involve skin, eye, and brain. It is the commonest phacomatosis associated with glaucoma that occurs at any time from birth to adulthood and arises from elevated episcleral venous pressure..$^{65,66}$ 
"Neurofibromatosis" is another phacomatosis that may present with iris abnormalities, like ectropion uveae and glaucoma, before the systemic disease is apparent. ${ }^{62,67}$

"Ectopia lentis", a displacement of the lens from its normal position due to distended or broken zonules, can present as an isolated ocular anomaly or be associated with other ocular or systemic findings (like Marfan syndrome, homocystinuria, and Weill-Marchesani syndrome). Glaucoma is a common and often a serious complication. The mechanism can be either angle closure from a displaced lens or an open-angle mechanism. ${ }^{68-70}$

"Congenital rubella syndrome" includes cardiac defects, neurologic abnormalities, bone defects, hepatosplenomegaly, and endocrine abnormalities. Ocular disease affects $78 \%-88 \%$ of congenital rubella syndrome patients and includes keratitis, corneal edema, iris hypoplasia, chronic iridocyclitis, cataracts, pigmentary retinopathy, and glaucoma that may be secondary to congenital malformation of the angle or to chronic iridocyclitis or cataracts. ${ }^{71}$

\section{Glaucoma associated with acquired conditions}

This category includes conditions which are not inherited or present at birth but which develop after birth.

Pediatric uveitis may cause glaucoma. The majority of cases of pediatric uveitis are idiopathic, while the most common identifiable cause of uveitis in children is juvenile idiopathic arthritis (41\%-67\%). Uveitic glaucoma is multifactorial due to chronic cellular trabecular obstruction, trabeculitis, and peripheral anterior synechiae. Children with uveitis develop more severe glaucoma than adults and they progress rapidly to severe visual loss. ${ }^{72-74}$

Traumatic glaucoma, acute or chronic in onset, are secondary to blunt or penetrating ocular trauma. The pathogenesis is multifactorial and the mechanisms of raised IOP include uveitis, hyphema, angle recession, ghost-cell glaucoma, and dislocated lens. ${ }^{75}$

"Corticosteroid-induced glaucoma" is an increase in IOP as a result of corticosteroid therapy. Increased IOP is time and dose dependent and may occur with various forms of corticosteroids (topical, inhaled, oral, etc). The pathogenesis is an increased resistance to outflow of aqueous resulting from changes in TM microstructure due to an abnormal extracellular protein deposition. ${ }^{76}$

Glaucoma secondary to intraocular tumors in children is a relatively rare event. Patients with acquired glaucoma secondary to tumors can be symptomatic with acute glaucoma due to the fast growth of the tumor, or symptom-free in case of a progressive, slow growing tumor. Retinoblastoma and intraocular melanoma are the most common malignant tumors leading to secondary glaucoma, due to outflow obstruction by tumor cells or secondary hemorrhage. ${ }^{77,78}$

Retinopathy of prematurity (ROP)-induced glaucoma occurring in an eye with a history of ROP and anatomic changes due to the ROP (retrolental fibroplasia, papillary block) or treatment for ROP (choroidal detachment, anterior displacement of the lens-iris diaphragm, hyphema). The mechanisms of raised IOP can all result in narrowing of the AC angle with the potential for secondary angle closure. $^{79,80}$

\section{Glaucoma following cataract surgery}

Glaucoma is one of the most serious complications occurring after infantile cataract surgery for congenital idiopathic cataract, cataract associated with ocular or systemic syndromes, or acquired cataract. It is usually open angle and can develop during the immediate postoperative period or years later. It includes both aphakic and pseudophakic eyes. Although early cataract surgery has been shown to be associated with improved visual outcomes, it is also important to remember that the earlier cataract surgery is performed, the higher is the risk of secondary glaucoma.

\section{Medical therapy}

Medical therapy is generally used as temporizing IOPlowering treatment before surgery or as adjuvant treatment postoperatively in case of partially successful procedures for refractory glaucoma in infants and young children. Corneal edema resolution, thanks to aqueous suppression prior to surgery, is another important achievable goal.

As a primary approach to childhood glaucoma, medication alone usually has a provisional efficacy, particularly in PCG. However, medical treatment should be considered firstline for JOAG, uveitis-related glaucoma, and glaucoma after cataract removal. Different kinds of childhood glaucoma may respond differently to topical hypotensive drugs (Table 2). In the case of PCG, universally recognized as a surgical condition, pharmacologic therapy may help to alleviate pain and photophobia and to recover corneal transparency for a better view of the AC angle, especially before angle surgery.

If a goniosurgery is planned, miosis induced with pilocarpine can increase angle opening, improving surgical accessibility and reducing consecutive anterior synechiae. Beta-blockers must be instilled with the lowest dosage and frequency, better if in gel formulation, because of cardiorespiratory side effects in children. ${ }^{81-85}$ Oral carbonic anhydrase inhibitors are not indicated for infants due to possible 
Table 2 Medication use in childhood glaucoma

\begin{tabular}{|c|c|c|c|}
\hline Drugs & Mechanism & Efficacy & Side effects \\
\hline Beta-blockers & $\begin{array}{l}\text { Aqueous decrease } \\
\text { - Ciliary epithelial inhibition } \\
\text { - Anterior ciliary artery vasoconstriction }\end{array}$ & $20 \%-25 \%$ IOP reduction & Topical: apnea, asthma, cough, bradycardia \\
\hline $\begin{array}{l}\text { Carbonic anhydrase } \\
\text { inhibitors }\end{array}$ & $\begin{array}{l}\text { Aqueous decrease } \\
\text { - } \mathrm{HCO}_{3}^{-} \text {and } \mathrm{CO}_{2} \text { interconversion } \\
\text { inhibition }\end{array}$ & $\begin{array}{l}>25 \% \text { IOP reduction } \\
\text { (oral }>\text { topical) }\end{array}$ & $\begin{array}{l}\text { Oral: lethargy, paresthesia, anorexia, diarrhea, } \\
\text { metabolic acidosis, urolithiasis, growth } \\
\text { suppression, enuresis, allergy } \\
\text { Topical: metabolic acidosis }\end{array}$ \\
\hline Adrenergic agonists & $\begin{array}{l}\text { Aqueous decrease } \\
\text { - Uveoscleral outflow increase }\end{array}$ & Short-term IOP reduction & $\begin{array}{l}\text { Topical: allergy, mydriasis, tachyarrhythmia } \\
\text { Brimonidine: CNS toxicity (lethargy, apnea) }\end{array}$ \\
\hline $\begin{array}{l}\text { Prostaglandin analogues } \\
\text { or prostamides }\end{array}$ & Uveoscleral outflow increase & $25 \%-35 \%$ IOP reduction & $\begin{array}{l}\text { Topical: eyelash growth, hyperemia, iris } \\
\text { pigmentation change, uveitis }\end{array}$ \\
\hline Miotics & $\begin{array}{l}\text { TM outflow increase } \\
\text { - Ciliary muscle stimulation }\end{array}$ & Miosis for angle surgery & Topical: miosis, myopic shift, brow ache \\
\hline
\end{tabular}

Abbreviations: CNS, central nervous system; IOP, intraocular pressure; TM, trabecular meshwork.

metabolic acidosis, urolithiasis, lethargy, paresthesia, and anorexia; topical formulations are less efficient but safer, especially brinzolamide ${ }^{86-90}$ Brimonidine, an adrenergic agonist, must be avoided in neonates, infants, and young children, in consideration of central nervous system toxicity. ${ }^{91-94}$ In PCG, prostaglandin analogus and prostamides are mainly used as adjunctive medication. ${ }^{95-98}$

JOAG is more responsive to topical anti-glaucoma therapies, with prostaglandin analogs or beta-blockers usually prescribed as first drugs.

The different systemic pharmacokinetics in children, due to high ocular/plasmatic volume ratio and metabolic immaturity, could result in atypical or unpredictable effects with topically applied glaucoma medications. Therefore, it is important to advise parents or caregivers to perform punctal occlusion to reduce systemic absorption, and to pay special attention to adverse symptoms because of children's inability to verbalize them. ${ }^{99-101}$

Limitations in performing visual-field and morphofunctional testing of the optic-nerve head in children make followup more complicated. Thus, it is necessary to consider all available data to choose or reassess the target IOP.

Considering the lack of safety and effectiveness evaluations in pediatric patients, implementation of legislation in the USA and the European Union has encouraged pediatric-specific product development and testing in the last few years. ${ }^{102}$

In pregnant/lactating glaucoma patients, an appropriate balance of the risk to the fetus during therapy against risks to the mother in case of treatment reduction or suspension is mandatory. In the first trimester, all medications should be avoided (especially prostaglandin analogues, due to an increased risk of miscarriage), whereas in the second and third trimesters beta-blockers, alpha agonists, topical carbonic anhydrase inhibitors, and parasympathomimetics (miotics) could be used. During lactation, the instillation of alpha agonists and oral carbonic anhydrase inhibitors is contraindicated ${ }^{103-106}$ (Table 3).

Finally, a surgical approach must be considered whenever medical therapies are revealed to be unsatisfactory in lessening the progression of optic-nerve damage. Nevertheless, if a risk of severe postoperative complications in end-stage glaucomas exists, it is more advisable to be content with partial IOP control.

\section{Surgical therapy}

Surgery is the nodal point of the management of refractory childhood glaucoma, so it is crucial to opt for a forwardlooking strategy, considering the long life expectancy of the child. In effect, the first surgery is often the child's best chance

Table 3 Side effects in the mother and baby attributed to antiglaucomatous drugs

\begin{tabular}{|c|c|}
\hline Drugs & Side effects \\
\hline Beta-blockers & $\begin{array}{l}\text { Bradycardia and cardiac arrhythmia in fetus } \\
\text { or breastfed child } \\
\text { Timolol is approved by the American } \\
\text { Academy of Pediatrics during lactation with } \\
\text { punctal occlusion }\end{array}$ \\
\hline Alpha agonists & $\begin{array}{l}\text { Central nervous system depression, apnea, } \\
\text { and hypotension in the neonate/infant }\end{array}$ \\
\hline $\begin{array}{l}\text { Carbonic anhydrase } \\
\text { inhibitors }\end{array}$ & $\begin{array}{l}\text { Possible teratogenic, metabolic acidosis in } \\
\text { the breastfed child } \\
\text { It is not known if they are excreted in the milk } \\
\text { Dorzolamide is approved by the American } \\
\text { Academy of Pediatrics during lactation with } \\
\text { punctal occlusion }\end{array}$ \\
\hline Prostaglandin analogues & Uterine contractions and premature labor \\
\hline Parasympathomimetics & Cholinergic effects in the newborn \\
\hline
\end{tabular}


of long-term success, so it is important to choose the most appropriate procedure, and it is better if this is performed by an experienced surgeon under safe general anesthesia. ${ }^{107-109}$

Childhood glaucoma surgery has a higher complication and failure rate than in adult patients because of ocular enlargement and an intense inflammatory and healing response. In particular, thin and elastic sclera predisposes to peritubular leakage and impedes the ability to fashion a sclera flap and facilitates AC collapse; thick Tenon capsule prevents good filtration; stretched zonules in enlarged eyes can cause lens subluxation; and limited orbital space makes access to the eye difficult. In addition, compliance and cooperation issues can negatively influence the quality of postoperative monitoring and follow-up.

Angle surgery (goniotomy, trabeculotomy) is usually the first-line procedure with the best success rates for PCG, whereas it is impractical in glaucoma associated with Axenfeld-Rieger anomaly because of iris attachments to Schwalbe's line as well as in uveitic glaucoma because of peripheral anterior synechiae. Pilocarpine preoperatively or acetylcholine chloride intraoperatively is advisable to achieve adequate miosis and protect the lens against trauma by the iris. "Goniotomy" is an ab interno angle incision under direct gonioscopy, but it is unfeasible with hazy corneas because the angle structures are not clearly visible, often even after epithelial debridement. Stromal haze and Haab striae may still obscure the view. Goniotomy has a low complication rate and is a very effective operation with a success usually ranging from $70 \%$ to $93 \%$ in large series after multiple surgeries. ${ }^{110-112}$ "Trabeculotomy" is the ab externo rupture of the TM obtained by dissecting a superficial scleral flap and then identifying and entering SC with a metal trabeculotome probe. Complications are related to the positioning and manipulation of the probe: stripping of Descemet's membrane, iris prolapse, iridodialysis, cyclodialysis, hyphema, bleb formation and hypotony, lens subluxation, and cataract. ${ }^{113}$

As the extent of angle incised is important in some cases, circumferential suture trabeculotomy with an illuminated microcatheter has been recently introduced to treat the entire angle in one session. This surgical technique has a reported overall success rate of $80 \%-90 \%$ after $1-4$ years. ${ }^{114,115}$

Combined trabeculotomy-trabeculectomy is sustained to be more successful than either procedure performed alone and that is the primary procedure of choice. ${ }^{116-118}$

Trabeculectomy can be performed as a primary surgical procedure with satisfactory success rates in cases of repeated failed angle surgery and in most secondary glaucomas. The application of mitomycin $\mathrm{C}$ (MMC) in refractory glaucomas can counteract the vigorous wound healing response in children, but the complications, especially those related to hypotony (shallow or flat $\mathrm{AC}$, hypotony maculopathy, choroidal effusion, suprachoroidal hemorrhage) and to bleb formation (blebitis, endophthalmitis, chronic bleb leak) often appear to increase. ${ }^{119-123}$

Aqueous shunt devices (Molteno, Ahmed, and Baerveldt implants) offer the most effective long-term IOP management in glaucomas that are refractory to other surgical solutions. In this procedure, a tube is connected to a reservoir (plate) that shunts aqueous from the $\mathrm{AC}$ to the equator. Even if available in smaller pediatric versions, the adult-size implant is recommended if obtainable to utilize a larger surface area. In eyes with heavily scarred conjunctiva, aqueous shunt surgery appears more appropriate. There is no prospective evidence that MMC influences shunt surgery outcomes. Despite the effectiveness, these devices have a severe complication profile related to hypotony (shallow or flat AC, hypotony maculopathy, choroidal effusion, suprachoroidal hemorrhage and phthisis) or to the tube (tube erosion, occlusion, migration, corneal touch, iris touch, and lens touch). Several studies have reported success rates around $80 \%$ with a mean follow-up of 2 years. Even with long-term well-controlled IOP, relapse can occur at any stage. ${ }^{124-131}$

Cyclophotocoagulation with a transscleral diode laser $(810 \mathrm{~nm})$ has a limited success rate in the long term and retreatment is often required, which disallows the discontinuation of medications. Cyclodestruction is usually indicated for challenging, refractory glaucomas with poor surgical prognoses. Complications associated with cyclodiode therapy include: hypotony, phthisis, conjunctival burns, uveitis, scleromalacia, cataract, retinal detachment, and loss of vision. ${ }^{132-134}$

Other glaucoma procedures (deep sclerectomy, viscocanalostomy, canaloplasty, ab interno trabeculotomy with Trabectome $^{\circledR}$ [NeoMedix Corporation, Tustin, CA, USA], suprachoroidal shunts, TM bypass shunts, and transscleral shunts) promoted in children have not been widely embraced because of either the technical complexity in buphthalmic eyes or not yet proven efficacy and safety in children. ${ }^{135-137}$

Combining glaucoma surgery with other ocular surgeries may potentially increase the risk of complications, prolong duration of anesthesia, and render less certain the outcomes. However, when more than one procedure is required, consecutive rather than simultaneous surgeries are preferable.

The variations in presentation will dictate when or if lens extraction and/or glaucoma surgery is/are necessary, generally favoring isolated glaucoma surgery, rather than 
combined procedures, to minimize risks. In all cases of planned corneal surgery, the IOP must be preemptively reduced. ${ }^{138}$ Following successful IOP control with surgery, ametropia correction and amblyopia therapy, if indicated, are essential to maximize visual potential. Regardless, it is important to prepare the patient and parents or caregivers for lifelong follow-up and possible future surgeries.

\section{Surgical interventions at the Eye Clinic of Verona, Italy}

During the period 2000-2013, we evaluated 123 children under general anesthesia at the Eye Clinic of Verona in Italy, 73 males (59\%) and 50 females (41\%), with an age at onset (mean \pm standard deviation) of $25 \pm 17$ months. In $12 \%$ of cases, the first diagnosis of primary $(54 \%)$ or secondary (46\%) glaucoma was made within the first month of life (Table 4). Considering 18 patients dropped out, the mean follow-up was $4.8 \pm 3.7$ years (range: $3-13$ years), with a mean of $102 \pm 15$ EUAs per year.

The first surgical approach utilized was goniotomy in $31 \%$ of cases, trabeculotomy alone in $36 \%$ of cases, and combined trabeculotomy-trabeculectomy with or without MMC in 33\% of cases. As further intervention, when needed, trabeculotomy, combined trabeculotomy-trabeculectomy, bleb needling, cyclodiode treatment (especially at the beginning of the study period), and Baerveldt device implantation were mainly performed.

In the case of primary glaucoma, a mean of 1.5 operations was executed, with a mean IOP of $16.1 \pm 4.2 \mathrm{mmHg}$ at last follow-up (27.8 $\pm 7.3 \mathrm{mmHg}$ at baseline); in case of secondary glaucoma, a mean of 3.2 operations was needed, with a mean

Table 4 Childhood glaucoma types evaluated in the Eye Clinic of Verona, Italy during the period 2000-2013

\begin{tabular}{ll}
\hline Childhood glaucoma & Patients, n/N (\%) \\
\hline Primary & $67 / 123(54)$ \\
Bilateral & $54 / 123$ \\
Monolateral & $13 / 123$ \\
Secondary & $56 / 123(46)$ \\
Glaucoma associated with ocular anomalies & $44 / 123(36)$ \\
or systemic disease & \\
Axenfeld-Rieger anomaly & $11 / 44$ \\
Sturge-Weber syndrome & $7 / 44$ \\
Aniridia & $5 / 44$ \\
Peters anomaly & $5 / 44$ \\
Rubinstein-Taybi syndrome & $2 / 44$ \\
Oculodentodigital dysplasia & $2 / 44$ \\
Unspecified & $12 / 44$ \\
Glaucoma following congenital cataract surgery & $12 / 123(10)$ \\
\hline
\end{tabular}

Abbreviations: $\mathrm{n}$, number of eyes; $\mathrm{N}$, sample size.
Table 5 Surgical approach and outcomes in cases of childhood glaucoma treated in the Eye Clinic of Verona, Italy, during the period 2000-2013 ( $\mathrm{N}=123)$

\begin{tabular}{|c|c|c|}
\hline $\begin{array}{l}\text { First glaucoma } \\
\text { surgery }\end{array}$ & n (\%) & $\begin{array}{l}\text { Further glaucoma } \\
\text { surgeries }\end{array}$ \\
\hline Goniotomy & $38(3 \mathrm{I})$ & Trabeculotomy \\
\hline Trabeculotomy & $44(36)$ & Trabeculotomy- \\
\hline $\begin{array}{l}\text { Trabeculotomy- } \\
\text { trabeculectomy }\end{array}$ & $4 \mid(33)$ & $\begin{array}{l}\text { trabeculectomy } \\
\text { Needling } \\
\text { Baerveldt implant } \\
\text { Cyclodiode }\end{array}$ \\
\hline $\begin{array}{l}\text { Childhood glaucoma } \\
\text { (mean number } \\
\text { of surgeries) }\end{array}$ & $\begin{array}{l}\text { Preoperative IOP } \\
\text { (mean } \mathrm{mmHg} \text { ) }\end{array}$ & $\begin{array}{l}\text { Final IOP } \\
\text { (mean } \mathrm{mmHg} \text { ) }\end{array}$ \\
\hline Primary (I.5) & $27.8 \pm 7.3$ & $16.1 \pm 4.2$ \\
\hline Secondary (3.2) & $26.6 \pm 8.1$ & $22.8 \pm 5.1$ \\
\hline
\end{tabular}

Data presented as mean \pm standard deviation.

Abbreviation: IOP, intraocular pressure; $\mathrm{N}$, sample size; $\mathrm{n}$, number of eyes.

IOP of $22.8 \pm 5.1 \mathrm{mmHg}$ at the last visit $(26.6 \pm 8.1 \mathrm{mmHg}$ preoperatively) (Table 5).

\section{Conclusion}

Childhood glaucoma is a challenging disease that needs an appropriate approach in dedicated centers with specific experienced surgeons. A good prognosis is a function of early diagnosis, proper surgical indication, and correct technical execution.

\section{Disclosure}

The authors declare no conflicts of interest in this work.

\section{References}

1. Yeung HH, Walton DS. Clinical classification of childhood glaucomas. Arch Ophthalmol. 2010;128(6):680-684.

2. Kong L, Fry M, Al-Samarraie M, Gilbert C, Steinkuller PG. An update on progress and the changing epidemiology of causes of childhood blindness worldwide. JAAPOS. 2012;16(6):501-507.

3. Dandona L, Williams JD, Williams BC, Rao GN. Population based assessment of childhood blindness in southern India. Arch Ophthalmol. 1998;116(4):545-546.

4. Gilbert CE, Rahi JS, Quinn GE. Visual impairment and blindness in children. In: Johnson GJ, Minassian DC, Weale RA, West SK, editors. The Epidemiology of Eye Disease. 2nd ed. London: Hodder Arnold; 2003:260-286.

5. Sarfarazi M, Stoilov I, Schenkman JB. Genetics and biochemistry of primary congenital glaucoma. Ophthalmol Clin North Am. 2003;16(4): 543-554.

6. Gage PJ, Rhoades W, Prucka SK, Hjalt T. Fate maps of neural crest and mesoderm in the mammalian eye. Invest Ophthalmol Vis Sci. 2005; 46(11):4200-4208.

7. McMenamin PG. A quantitative study of the prenatal development of the aqueous outflow system in the human eye. Exp Eye Res. 1991;53(4): 507-517.

8. Ramírez JM, Ramírez AI, Salazar JJ, Rojas B, De Hoz R, Triviño A. Schlemm's canal and the collector channels at different developmental stages in the human eye. Cells Tissues Organs. 2004;178(3): $180-185$. 
9. Wu SC, Huang SC, Kuo CL, Lin KK, Lin SM. Reversal of optic disc cupping after trabeculotomy in primary congenital glaucoma. Can $J$ Ophthalmol. 2002;37(6):337-341.

10. Honig MA, Barraquer J, Perry HD, Riquelme JL, Green WR. Forceps and vacuum injuries to the cornea: histopathologic features of twelve cases and review of the literature. Cornea. 1996;15(5):463-472.

11. Sun L. Early childhood general anaesthesia exposure and neurocognitive development. Br J Anaesth. 2010;105 Suppl 1:i61-i68.

12. Sun LS, Li G, DiMaggio CJ, et al. Feasibility and pilot study of the Pediatric Anesthesia NeuroDevelopment Assessment (PANDA) project. J Neurosurg Anesthesiol. 2012;24(4):382-388.

13. Self WG, Ellis PP. The effect of general anesthetic agents on intraocular pressure. Surv Ophthalmol. 1977;21(6):494-500.

14. Oberacher-Velten I, Prasser C, Rochon J, Ittner KP, Helbig H, Lorenz B. The effects of midazolam on intraocular pressure in children during examination under sedation. Br J Ophthalmol. 2011;95(8): 1102-1105.

15. Levy J, Lifshitz T, Rosen S, Tessler Z, Biedner BZ. Is the tono-pen accurate for measuring intraocular pressure in young children with congenital glaucoma? J AAPOS. 2005;9(4):321-325.

16. Bradfield YS, Kaminski BM, Repka MX, Melia M; Pediatric Eye Disease Investigator Group, et al. Comparison of Tono-Pen and Goldmann applanation tonometers for measurement of intraocular pressure in healthy children. JAAPOS. 2012;16(3):242-248.

17. Eisenberg DL, Sherman BG, McKeown CA, Schuman JS. Tonometry in adults and children. A manometric evaluation of pneumatonometry, applanation, and TonoPen in vitro and in vivo. Ophthalmology. 1998;105(7):1173-1181

18. García-Resúa C, González-Meijome JM, Gilino J, Yebra-Pimentel E. Accuracy of the new ICare rebound tonometer vs other portable tonometers in healthy eyes. Optom Vis Sci. 2006;83(2):102-107.

19. Kageyama M, Hirooka K, Baba T, Shiraga F. Comparison of ICare rebound tonometer with noncontact tonometer in healthy children. J Glaucoma. 2011;20(1):63-66.

20. Lundvall A, Svedberg H, Chen E. Application of the ICare rebound tonometer in healthy infants. J Glaucoma. 2011;20(1):7-9.

21. Flemmons MS, Hsiao YC, Dzau J, Asrani S, Jones S, Freedman SF. Icare rebound tonometry in children with known and suspected glaucoma JAAPOS. 2011;15(2):153-157.

22. Dahlmann-Noor AH, Puertas R, Tabasa-Lim S, et al. Comparison of handheld rebound tonometry with Goldmann applanation tonometry in children with glaucoma: a cohort study. BMJ Open. 2013;3(4):pii:e001788.

23. Poostchi A, Mitchell R, Nicholas S, Purdie G, Wells A. The iCare rebound tonometer: comparisons with Goldmann tonometry, and influence of central corneal thickness. Clin Experiment Ophthalmol. 2009;37(7):687-691.

24. Martinez-de-la-Casa JM, Garcia-Feijoo J, Saenz-Frances F, et al. Comparison of rebound tonometer and Goldmann handheld applanation tonometer in congenital glaucoma. J Glaucoma. 2009;18(1): $49-52$.

25. Anderson DR. Pathology of the glaucomas. Br J Ophthalmol. 1972; 56(3):146-157.

26. Anderson DR. The development of the trabecular meshwork and its abnormality in primary infantile glaucoma. Trans Am Ophthalmol Soc. 1981;79:458-485.

27. Hansson HA, Jerndal T. Scanning electron microscopic studies on the development of the iridocorneal angle in human eyes. Invest Ophthalmol. 1971;10(4):252-265.

28. Pediatric Eye Disease Investigator Group, Bradfield YS, Melia BM, et al. Central corneal thickness in children. Arch Ophthalmol. 2011; 129(9):1132-1138.

29. Brandt JD, Beiser JA, Kass MA, Gordon MO. Central Corneal Thickness in the Ocular Hypertension Treatment Study (OHTS). Ophthalmology. 2001;108(10): 1779-1788

30. Wygnanski-Jaffe T, Barequet IS. Central corneal thickness in congenital glaucoma. Cornea. 2006;25(8):923-925.
31. Brandt JD, Casuso LA, Budenz DL. Markedly increased central corneal thickness: an unrecognized finding in congenital aniridia. $A m ~ J$ Ophthalmol. 2004;137(2):348-350.

32. Muir KW, Duncan L, Enyedi LB, Wallace DK, Freedman SF. Central corneal thickness: congenital cataracts and aphakia. Am J Ophthalmol. 2007;144(4):502-506.

33. Lupinacci AP, da Silva Jordão ML, Massa G, Arieta CE, Costa VP. Central corneal thickness in children with congenital cataract and children with surgical aphakia: a case-control study. Br J Ophthalmol. 2009;93(3):337-341.

34. Chen TC, Walton DS, Bhatia LS. Aphakic glaucoma after congenital cataract surgery. Arch Ophthalmol. 2004;122(12):1819-1825.

35. Richardson KT, Shaffer RN. Optic-nerve cupping in congenital glaucoma. Am J Ophthalmol. 1966;62(3):507-509.

36. Richardson KT. Optic cup symmetry in normal newborn infants. Invest Ophthalmol. 1968;7(2):137-140.

37. Shaffer RN, Hetherington J Jr. The glaucomatous disc in infants. A suggested hypothesis for disc cupping. Trans Am Acad Ophthalmol Otolaryngol. 1969;73(5):923-935.

38. Sampaolesi R. Corneal diameter and axial length in congenital glaucoma. Can J Ophthalmol. 1988;23(1):42-44.

39. Law SK, Bui D, Caprioli J. Serial axial length measurements in congenital glaucoma. Am J Ophthalmol. 2001;132(6):926-928.

40. Kiefer G, Schwenn O, Grehn F. Correlation of postoperative axial length growth and intraocular pressure in congenital glaucoma: a retrospective study in trabeculotomy and goniotomy. Graefes Arch Clin Exp Ophthalmol. 2001;239(12):893-899.

41. Panarello SM, Priolo E, Vittone P. Pediatric ultrasound: a personal experience during the period 1991-1994. Ophthalmologica. 1998; 212 Suppl 1:115-117.

42. Kiskis AA, Markowitz SN, Morin JD. Corneal diameter and axial length in congenital glaucoma. Can J Ophthalmol. 1985;20(3):93-97.

43. Kim TW, Kim M, Weinreb RN, Woo SJ, Park KH, Hwang JM. Optic disc change with incipient myopia of childhood. Ophthalmology. 2012;119(1):21-26. e1-e3.

44. Taylor RH, Ainsworth JR, Evans AR, Levin AV. The epidemiology of pediatric glaucoma: the Toronto experience. J AAPOS. 1999;3(5): 308-315.

45. Papadopoulos M, Cable N, Rahi J, Khaw PT; BIG Eye Study Investigators. The British Infantile and Childhood Glaucoma (BIG) Eye Study. Invest Ophthalmol Vis Sci. 2007;48(9):4100-4106.

46. McGinnity FG, Page AB, Bryars JH. Primary congenital glaucoma: twenty years experience. Ir J Med Sci. 1987;156(12):364-365.

47. François J. Congenital glaucoma and its inheritance. Ophthalmologica. 1980;181(2):61-73

48. Gencík A. Epidemiology and genetics of primary congenital glaucoma in Slovakia. Description of a form of primary congenital glaucoma in gypsies with autosomal-recessive inheritance and complete penetrance. Dev Ophthalmol. 1989;16:76-115.

49. Walton DS, Nagao K, Yeung HH, Kane SA. Late-recognized primary congenital glaucoma. J Pediatr Ophthalmol Strabismus. 2013;50(4):235-238.

50. Narooie-Nejad M, Chitsazian F, Khoramian Tusi B, et al. Genotyping results of Iranian PCG families suggests one or more PCG locus other than GCL3A, GCL3B, and GCL3C exist. Mol Vis. 2009;15: 2155-2161.

51. Sarfarazi M, Stoilov I. Molecular genetics of primary congenital glaucoma. Eye (Lond). 2000;14(Pt 3B):422-428.

52. Khan AO. Genetics of primary glaucoma. Curr Opin Ophthalmol. 2011;22(5):347-355.

53. Barkan O. Pathogenesis of congenital glaucoma: gonioscopic and anatomic observation of the angle of the anterior chamber in the normal eye and in congenital glaucoma. Am J Ophthalmol. 1955;40(1):1-11.

54. Worst JGF. Congenital glaucoma. Remarks on the aspect of chamber angle, ontogenetic and pathogenetic background, and mode of action of goniotomy. Invest Ophthalmol. 1968;7(2):127-134. 
55. Perry LP, Jakobiec FA, Zakka FR, Walton DS. Newborn primary congenital glaucoma: histopathologic features of the anterior chamber filtration angle. JAAPOS. 2012;16(6):565-568.

56. Su CC, Liu YF, Li SY, Yang JJ, Yen YC. Mutations in the CYP1B1 gene may contribute to juvenile-onset open angle glaucoma. Eye (Lond). 2012;26(10):1369-1377.

57. Axenfeld T. Embryotoxon cornea posterius. Klin Monatsbl Augenheilkd. 1920;65:381-382

58. Reiger H. Verlagerung and Schlitzform der Pupille mit Hypoplasie des Irisvorderblattes [Shift and slit shape of the pupil with iris hypoplasia of the front sheet]. Z Augenheilkd. 1934;84:98-103. German.

59. Ozeki H, Shirai S, Nozaki M, et al. Ocular and systemic features of Peters' anomaly. Graefes Arch Clin Exp Ophthalmol. 2000;238(10): 833-839.

60. Lee H, Khan R, O'Keefe M. Aniridia: current pathology and management. Acta Ophthalmol. 2008;86(7):708-715.

61. August PS, Niederberger H, Helbig H. Progression of congenital ectropion uveae. Arch Ophthalmol. 2003;121(10):1511.

62. Edward DP, Morales J, Bouhenni RA, et al. Congenital ectropion uvea and mechanisms of glaucoma in neurofibromatosis type 1: new insights. Ophthalmology. 2012;119(7):1485-1494.

63. Pollard ZF. Persistent hyperplastic primary vitreous: diagnosis, treatment and results. Trans Am Ophthalmol Soc. 1997;95:487-549.

64. Chattopadhyay A, Kher AS, Bharucha BA, Nicholson AD. Microcornea, glaucoma, and absent frontal sinus. J Pediatr. 1995;127(2):333.

65. Bodensteiner JB, Roach ES. Sturge-Weber syndrome: introduction and overview. In: Bodensteiner JB, Roach ES, editors. Sturge-Weber Syndrome. 2nd ed. Mt Freedom, NJ: Sturge-Weber Foundation; 2010, pp. 1-10.

66. Shiau T, Armogan N, Yan DB, Thomson HG, Levin AV. The role of episcleral venous pressure in glaucoma associated with Sturge-Weber syndrome. JAAPOS. 2012;16(1):61-64.

67. Morales J, Chaudhry IA, Bosley TM. Glaucoma and globe enlargement associated with neurofibromatosis type 1. Ophthalmology. 2009;116(9):1725-1730.

68. Loeys BL, Dietz HC, Braverman AC, et al. The revised Ghent nosology for the Marfan syndrome. J Med Genet. 2010;47(7):476-485.

69. Dagi LR, Walton DS. Anterior axial lens subluxation, progressive myopia, and angle closure glaucoma: recognition and treatment of atypical presentation of ectopia lentis. J AAPOS. 2006;10(4):345-350.

70. Fuchs J, Rosenberg T. Congenital ectopia lentis. A Danish national survey. Acta Ophthalmol Scand. 1998;76(1):20-26.

71. Mets MB, Chhabra MS. Eye manifestations of intrauterine infections and their impact on childhood blindness. Surv Ophthalmol. 2008;53(2):95-111.

72. Chebil A, Chaabani L, Kort F, Ben Youssef N, Turki F, El Matri L. [Epidemiologic study of pediatric uveitis: a series of 49 cases]. $J \mathrm{Fr}$ Ophtalmol. 2012;35(1):30-34. French.

73. Edelsten C, Reddy MA, Stanford MR, Graham EM. Visual loss associated with pediatric uveitis in English primary and referral centers. $\mathrm{Am}$ J Ophthalmol. 2003;135(5):676-680.

74. Kim SJ. Diagnosis and management of noninfectious pediatric uveitis. Int Ophthalmol Clin. 2011;51(1):129-145.

75. De Leon-Ortega JE, Girkin CA. Ocular trauma-related glaucoma. Ophthalmol Clin North Am. 2002;15(2):215-223.

76. Jones R 3rd, Rhee DJ. Corticosteroid-induced ocular hypertension and glaucoma: A brief review and update of the literature. Curr Opin Ophthalmol. 2006;17(2):163-167.

77. Shields CL, Shields JA, Shields MB, Augsburger JJ. Prevalence and mechanisms of secondary intraocular pressure elevation in eyes with intraocular tumors. Ophthalmology. 1987;94(7):839-846.

78. Kashyap S, Meel R, Pushker N, et al. Clinical predictors of high risk histopathology in retinoblastoma. Pediatr Blood Cancer. 2012;58(3):356-361.

79. Bremer D, Rogers D, Good W, Tung B, Hardy R, Fellows R. Glaucoma in the Early Treatment for Retinopathy of Prematurity (ETROP) study. JAAPOS. 2012;16(5):449-452.
80. Uehara A, Kurokawa T, Gotoh N, Yoshimura N, Tokushima T. Angle closure glaucoma after laser photocoagulation for retinopathy of prematurity. Br J Ophthalmol. 2004;88(8):1099-1100.

81. Olson RJ, Bromberg BB, Zimmerman TJ. Apneic spells associated with timolol therapy in a neonate. Am J Ophthalmol. 1979;88(1):120-122.

82. Hoskins HD Jr, Hetherington J Jr, Magee SD, Naykhin R, Migliazzo CV. Clinical experience with timolol in childhood glaucoma. Arch Ophthalmol. 1985;103(8):1163-1165.

83. Zimmerman TJ, Kooner KS, Morgan KS. Safety and efficacy of timolol in pediatric glaucoma. Surv Ophthalmol. 1983;28 Suppl:262-264.

84. Passo MS, Palmer EA, Van Buskirk EM. Plasma timolol in glaucoma patients. Ophthalmology. 1984;91(11):1361-1363.

85. Plager DA, Whitson JT, Netland PA, et al. Betaxolol hydrochloride ophthalmic suspension $0.25 \%$ and timolol gel-forming solution $0.25 \%$ and $0.5 \%$ in paediatric glaucoma: a randomized clinical trial. JAAPOS. 2009;13(4):384-390.

86. Kaur IP, Smitha R, Aggarwal D, Kapil M. Acetazolamide: future perspective in topical glaucoma therapeutics. Int J Pharm. 2002; 248(1-2):1-14.

87. Portellos M, Buckley EG, Freedman SF. Topical versus oral carbonic anhydrase inhibitor therapy for pediatric glaucoma. JAAPOS. 1998;2(1):43-47.

88. Ott EZ, Mills MD, Arango S, Getson AJ, Assaid CA, Adamsons IA. A randomized trial assessing dorzolamide in patients with glaucoma who are younger than 6 years. Arch Ophthalmol. 2005;123(9):1177-1186.

89. Whitson JT, Roarty JD, Vijaya L, et al. Efficacy of brinzolamide and levobetaxolol in pediatric glaucomas: a randomized clinical trial. JAAPOS. 2008;12(3):239-246.

90. Sabri K, Levin AV. The additive effect of topical dorzolamide and systemic acetazolamide in pediatric glaucoma. JAAPOS. 2006;10(5): 464-468.

91. Carlsen JO, Zabriskie NA, Kwon YH, Barbe ME, Scott WE. Apparent central nervous system depression in infants after the use of topical brimonidine. Am J Ophthalmol. 1999;128(2):255-256.

92. Mungan NK, Wilson TW, Nischal KK, Koren G, Levin AV. Hypotension and bradycardia in infants after the use of topical brimonidine and betablockers. JAAPOS. 2003;7(1):69-70.

93. Lai Becker M, Huntington N, Woolf AD. Brimonidine tartrate poisoning in children: frequency, trends, and use of naloxone as an antidote. Pediatrics. 2009;123(2):e305-e311.

94. Al-Shahwan S, Al-Torbak AA, Turkmani S, Al-Omran M, Al-Jadaan I, Edward DP. Side-effect profile of brimonidine tartrate in children. Ophthalmology. 2005;112(12):2143.

95. Yanovitch TL, Enyedi LB, Schotthoeffer EO, Freedman SF. Travoprost in children: adverse effects and intraocular pressure response. JAAPOS. 2009;13(1):91-93.

96. Maeda-Chubachi T1, Chi-Burris K, et al; A6111137 Study Group. Comparison of latanoprost and timolol in pediatric glaucoma: a phase 3, 12-week, randomized, double-masked multicenter study. Ophthalmology. 2011;118(10):2014-2021.

97. Black AC, Jones S, Yanovitch TL, Enyedi LB, Stinnett SS, Freedman SF. Latanoprost in pediatric glaucoma: pediatric exposure over a decade. J AAPOS. 2009;13(6):558-562.

98. Raber S, Courtney R, Maeda-Chubachi T, et al. Latanoprost systemic exposure in pediatric and adult patients with glaucoma: a phase 1, open-label study. Ophthalmology. 2011;118(10):2022-2027.

99. American Academy of Pediatrics Committee on Drugs. Transfer of drugs and other chemicals into human milk. Pediatrics. 2001;108(3): 776-789.

100. Coppens G, Stalmans I, Zeyen T, Casteels I. The safety and efficacy of glaucoma medication in the pediatric population. J Pediatr Ophthalmol Strabismus. 2009;46(1):12-18.

101. Moore W, Nischal KK. Pharmacologic management of glaucoma in childhood. Paediatr Drugs. 2007;9(2):71-79.

102. Fortinguerra F, Clavenna A, Bonati M. Ocular medicines in children: the regulatory situation related to clinical research. BMC Pediatr. 2012;12:8. 
103. Maris PJ Jr, Mandal AK, Netland PA. Medical therapy of pediatric glaucoma and glaucoma in pregnancy. Ophthalmol Clin North Am. 2005;18(3):461-468.

104. Razeghinejad MR, Tania Tai TY, Fudemberg SJ, Katz LJ. Pregnancy and glaucoma. Surv Ophthalmol. 2011;56(4):324-335.

105. Brauner SC, Chen TC, Hutchinson BT, Chang MA, Pasquale LR, Grosskreutz CL. The course of glaucoma during pregnancy: a retrospective case series. Arch Ophthalmol. 2006;124(8): 1089-1094.

106. Mendez-Hernandez C, Garcia-Feijoo J, Saenz-Frances F, et al. Topical intraocular pressure therapy effects on pregnancy. Clin Ophthalmol. 2012;6:1629-1632.

107. Khaw PT, Freedman S, Gandolfi S. Management of congenital glaucoma. J Glaucoma. 1999;8(1):81-85.

108. Aponte EP, Diehl N, Mohney BG. Medical and surgical outcomes in childhood glaucoma: a population-based study. J AAPOS 2011;15(3):263-267.

109. Ou Y, Caprioli J. Surgical management of pediatric glaucoma. Dev Ophthalmol. 2012;50:157-172.

110. Litinsky SM, Shaffer RN, Hetherington J, Hoskins HD. Operative complications of goniotomy. Trans Sect Ophthalmol Am Acad Ophthalmol Otolaryngol. 1977;83(1):78-79.

111. Kulkarni SV, Damji KF, Fournier AV, Pan I, Hodge WG. Endoscopic goniotomy: early clinical experience in congenital glaucoma. J Glaucoma. 2010;19(4):264-269.

112. Bowman RJ, Dickerson M, Mwende J, Khaw PT. Outcomes of goniotomy for primary congenital glaucoma in East Africa. Ophthalmology. 2011;118(2):236-240.

113. Allen L, Burian HM. Trabeculotomy ab externo. A new glaucoma operation: technique and results of experimental surgery. Am J Ophthalmol. 1962;53:19-26.

114. Beck AD, Lynch MG. 360 degrees trabeculotomy for primary congenital glaucoma. Arch Ophthalmol. 1995;113(9):1200-1202.

115. Beck AD, Lynn MJ, Crandall J, Mobin-Uddin O. Surgical outcomes with 360-degree suture trabeculotomy in poor-prognosis primary congenital glaucoma and glaucoma associated with congenital anomalies or cataract surgery. J AAPOS. 2011;15(1):54-58.

116. Luntz MH, Livingston DG. Trabeculotomy ab externo and trabeculectomy in congenital and adult-onset glaucoma. Am J Ophthalmol. 1977;83(2):174-179.

117. Mandal AK, Naduvilath TJ, Jayagandan A. Surgical results of combined trabeculotomy-trabeculectomy for developmental glaucoma. Ophthalmology. 1998;105(6):974-982.

118. Mandal AK, Bhatia PG, Gothwal VK, et al. Safety and efficacy of simultaneous bilateral primary combined trabeculotomytrabeculectomy for developmental glaucoma. Indian J Ophthalmol. 2002;50(1):13-19.

119. Gressel MG, Heuer DK, Parrish RK 2nd. Trabeculectomy in young patients. Ophthalmology. 1984;91(10):1242-1246

120. Freedman SF, McCormick K, Cox TA. Mitomycin C-augumented trabeculectomy with postoperative wound modulation in pediatric glaucoma. JAAPOS. 1999;3(2):117-124.

121. Sidoti PA, Belmonte SJ, Liebmann JM, Ritch R. Trabeculectomy with mitomycin-C in the treatment of pediatric glaucomas. Ophthalmology 2000;107(3):422-429.
122. Susanna R Jr, Oltrogge EW, Carani JC, Nicolela MT. Mitomycin as adjunct chemotherapy with trabeculectomy in congenital and developmental glaucomas. J Glaucoma. 1995;4(3):151-157.

123. Solus JF, Jampel HD, Tracey PA, et al. Comparison of limbus-based and fornix-based trabeculectomy: success, bleb-related complications, and bleb morphology. Ophthalmology. 2012;119(4):703-711.

124. Beck AD, Freedman S, Kammer J, Jin J. Aqueous shunt devices compared with trabeculectomy with Mitomycin-C for children in the first two years of life. Am J Ophthalmol. 2003;136(6):994-1000.

125. Cunliffe IA, Molteno AC. Long-term follow-up of Molteno drains used in the treatment of glaucoma presenting in childhood. Eye (Lond). 1998;12(Pt 3a):379-385

126. Fellenbaum PS, Sidoti PA, Heuer DK, Minckler DS, Baerveldt G, Lee PP. Experience with the Baerveldt implant in young patients with complicated glaucomas. J Glaucoma. 1995;4(2):91-97.

127. Al-Mobarak F, Khan AO. Two-year survival of Ahmed valve implantation in the first 2 years of life with and without intraoperative mitomycin-C. Ophthalmology. 2009;116(10):1862-1865.

128. Nassiri N, Nouri-Mahdavi K, Coleman AL. Ahmed glaucoma valve in children: A review. Saudi J Ophthalmol. 2011;25(4):317-327.

129. O’Malley Schotthoefer E, Yanovitch TL, Freedman SF. Aqueous drainage device surgery in refractory pediatric glaucomas: I. Long-term outcomes. JAAPOS. 2008;12(1):33-39.

130. Ou Y, Yu F, Law SK, Coleman AL, Caprioli J. Outcomes of Ahmed glaucoma valve implantation in children with primary congenital glaucoma. Arch Ophthalmol. 2009;127(11):1436-1441.

131. van Overdam KA, de Faber JT, Lemij HG, de Waard PW. Baerveldt glaucoma implant in paediatric patients. Br J Ophthalmol. 2006;90(3): 328-332.

132. Bock CJ, Freedman SF, Buckley EG, Shields MB. Transscleral diode laser cyclophotocoagulation for refractory pediatric glaucomas. J Pediatr Ophthalmol Strabismus. 1997;34(4):235-239.

133. Kirwan JF, Shah P, Khaw PT. Diode laser cyclophotocoagulation: role in the management of refractory pediatric glaucomas. Ophthalmology. 2002;109(2):316-323.

134. Autrata R, Rehurek J. Long-term results of transscleral cyclophotocoagulation in refractory pediatric glaucoma patients. Ophthalmologica. 2003;217(6):393-400.

135. Luke C, Dietlein TS, Jacobi PC, Konen W, Krieglstein GK. Risk profile of deep sclerectomy for treatment of refractory congenital glaucomas. Ophthalmology. 2002;109(6):1066-1071.

136. Noureddin BN, El-Haibi CP, Cheikha A, Bashshur ZF. Viscocanalostomy versus trabeculotomy ab externo in primary congenital glaucoma: 1-year follow-up of a prospective controlled pilot study. $\mathrm{Br} \mathrm{J} \mathrm{Oph-}$ thalmol. 2006;90(10):1281-1285.

137. Minckler D, Baerveldt G, Ramirez MA, et al. Clinical results with the Trabectome, a novel surgical device for treatment of open-angle glaucoma. Trans Am Ophthalmol Soc. 2006;104:40-50.

138. Lowe MT, Keane MC, Coster DJ, Williams KA. The outcome of corneal transplantation in infants, children, and adolescents. Ophthalmology. 2011;118(3):492-497.
Pediatric Health, Medicine and Therapeutics

\section{Publish your work in this journal}

Pediatric Health, Medicine and Therapeutics is an international, peerreviewed, open access journal publishing original research, reports, editorials, reviews and commentaries. All aspects of health maintenance preventative measures and disease treatment interventions are addressed within the journal. Practitioners from all disciplines are invited to submit

\section{Dovepress}

their work as well as healthcare researchers and patient support groups The manuscript management system is completely online and includes a very quick and fair peer-review system. Visit http://www.dovepress.com/ testimonials.php to read real quotes from published authors. 